\title{
Apoiando a Oferta de Informações sobre Transporte Coletivo Rodoviário através de uma Ontologia
}

\author{
Supporting the Information Supply on Collective Road Transport through an Ontology
}

Luiz Geraldo dos Santos Júnior ${ }^{\dagger *}$, Anrafel Fernandes Pereira ${ }^{\dagger}$

Como citar esse artigo. Dos Santos

Junior LG; Pereira AF. Apoiando a Oferta de Informações sobre Transporte Coletivo Rodoviário através de uma Ontologia. Revista Teccen. 2017 Jul/ Dez.; 10 (1): 10-23.

\begin{abstract}
Resumo
As redes de transporte de coletivo são de extrema importância para as cidades, porque é a partir delas que ocorre uma definição no que se refere às alternativas de deslocamento disponíveis à população. Entretanto, existe ainda um grande déficit em relação às informações precisas a respeito desses transportes para a população, sendo muitas das vezes inexistentes e desatualizadas. Tudo isso, acaba ocasionando transtornos e dificuldades para as pessoas que necessitam utilizar o serviço. Neste trabalho foi investigado o uso de ontologia para representação do conhecimento sobre redes de transporte coletivo rodoviário. O uso de ontologia neste contexto tem por objetivo trazer mais semântica e apoiar a distribuição de informações acerca dos transportes coletivos em uma cidade. Para isso, uma ontologia denominada OTNet foi desenvolvida e é apresentada neste trabalho.

Palavras-Chave: Representação de Conhecimento; Ontologia; Rede Transporte Coletivo Rodoviário; Protégé.
\end{abstract}

\section{Introdução}

As redes de transporte coletivo são de extrema importância para o desenvolvimento das cidades. Percebe-se que na medida em que as cidades evoluem, elas se tornam cada vez mais necessárias. Tudo isso, devido a proporcionar uma série de benefícios a todos os segmentos que compõem a sociedade. Além disso, as redes de transporte coletivo podem e vem afetando inclusive a qualidade de vida de uma cidade, porque a partir dela é que ocorre uma definição sobre como as alternativas de deslocamento disponível a população estarão disponíveis (Ramalho, 2010).

Outro fator em que existe um grande déficit é em relação às informações precisas a respeito do transporte coletivo. Apesar de encontrar vários trabalhos na literatura sobre $\mathrm{o}$ assunto, como por exemplo, aplicativos móveis que procuram ofertar informações a respeito dos horários e linhas de ônibus (Schaefer, 2004), na maioria das vezes as informações existentes são pouco precisas e desatualizadas. Além disso, outro grande problema é que normalmente há muitas informações armazenadas em diferentes bases de dados, dificultando o consumo destas informações pela população. Tudo isso, acaba ocasionando transtornos e dificuldades para as pessoas que necessitam utilizar o serviço público de transporte e ainda gera dificuldades em sua gestão por parte das empresas (Pinto, 2015).

Ontologias vêm sendo utilizadas há algum tempo na área da computação, principalmente em Inteligência Artificial, por viabilizar o

Afiliação dos autores: † Universidade Severino Sombra - USS, Vassouras - RJ, Brasil.

*jr.luzam@yahoo.com.br 
desenvolvimento de aplicações computacionais mais poderosas e inteligentes (Rocha, 2012). Uma Ontologia pode ser definida como um conjunto de conceitos fundamentais e suas relações, que capta como as pessoas entendem ou interpretam um determinado domínio, permitindo a representação de tal entendimento de maneira formal, compreensível por humanos e computadores (Isotani \& Bittencourt, 2015). O uso de ontologias em sistemas computacionais colabora para a criação de uma estrutura de dados conectados, sendo ela parte da proposta da Web Semântica, conforme recomendação do $\mathrm{W} 3 \mathrm{C}$.

Conforme mencionado acima, ontologias têm sidodesenvolvidas para facilitaro compartilhamento e reutilização de informações (Guarino, 1998) e vêm sendoutilizadaspararepresentação de conhecimento em diversos contextos, como por exemplo, em bibliotecas digitais, em sistemas computacionais para classificação de vulnerabilidade, aplicações científicas, portais de notícias, entre outros (Rocha, 2012).

O objetivo deste trabalho é desenvolver uma ontologia para representação de conhecimento sobre redes de transporte coletivo rodoviário, de tal forma que essa ontologia possa apoiar a oferta de informações aos usuários e facilitar a recuperação de dados referentes a ônibus, rotas, horários, entre outros. Acredita-se que com o apoio desta ontologia seja possível construir uma rede semântica para representação do conhecimento de uma rede de transporte coletivo e obter informações mais precisas e significativas sobre o contexto em que certo ônibus encontra-se, e ainda, descobrir determinadas informações que possam ser utilizadas posteriormente para aprimoramento do serviço e informações para usuários. Para isso, foi criada uma ontologia denominada OTNet. A OTNet apresenta informações essenciais sobre uma rede de transporte coletivo rodoviário, tais como, informações sobre rotas, horários, linhas, pontos de paradas, entre outras. A partir dela é possível inferir novos conhecimentos sobre este domínio de transporte.

Este artigo está dividido da seguinte maneira: na seção 2, a metodologia de pesquisa é apresentada. Nela, é explorada ainda, formas de representação de conhecimento em Inteligência Artificial dando destaque ao uso de ontologias. Os benefícios de utilização de uma ontologia no domínio de transporte coletivo rodoviário também são apresentados na seção 2 , bem como as ferramentas para apoiar a construção de ontologias e a metodologia utilizada neste processo. Na seção 3, a OTNet é apresentada. Detalhes sobre sua implementação e um cenário de uso também é explorado nesta seção. Por fim, na seção 4 são apresentadas as considerações finais e possíveis trabalhos futuros para este estudo.

\section{Metodologia}

Uma revisão da literatura foi realizada, como propósito de identificar formas de representação de conhecimento e identificar ferramentas que apoiassem o desenvolvimento desta atividade para descrever o conhecimento inicial sobre uma rede de transporte coletivo rodoviário. Após a realização desta revisão, foi observado que o uso de ontologia seria o mais apropriado, devido à mesma apresentar grande aplicação e ser mais utilizada, colaborando com bons resultados em diferentes cenários de aplicação (Isotani \& Bittencourt, 2015).

Em sequência foi procurado por uma metodologia para o desenvolvimento da ontologia que é apresentada neste trabalho, chamada de OTNet. Porém não foi encontrada uma metodologia formal para realizar esta atividade, ou seja, algo padronizado, logo, foi adotado a utilização dos sete passos propostos por Baaderet al. (2003), com o intuito de facilitar essa criação.

O passo seguinte compreendeu a escolha da ferramenta para realizar a atividade de construção da ontologia OTNet. A ferramenta escolhida foi o Protégé. Através dela foi possível realizar o desenvolvimento da ontologia utilizando todos os requisitos considerados essências para o primeiro protótipo, e fornecimento de alguns dados em caráter de teste para demonstração da potencialidade da máquina de inferência.

\section{Representação do Conhecimento}

Em Inteligência Artificial - IA, o termo "conhecimento" significa a informação que um programa de computador necessita para que possa comportar-seinteligentemente(Brachman, 1990).As interpretações de "representação de conhecimento" e seu papel em IA variam bastante, mas a questão central, segundo Brachman (1990) é a seguinte: "como transmitir o conhecimento do mundo para um robô ou outro sistema computacional, dandolhe uma capacidade adequada de raciocínio, de 
modoque este conhecimento possa ser utilizado para permitir ao sistema uma adaptação e exploração do seu ambiente?".

De uma forma genérica, pode-se entender representação do conhecimento como uma maneira de representar um conhecimento sobre determinado problema de maneira que possa ser entendido pela "máquina-computador". A literatura apresenta diversas formas de representação de conhecimento. Entre elas,citam-se: através de Lógica, Frames, Redes Semânticas, Ontologias, entre outras.

Lógica Simbólica: representada por John McCarthy, esta abordagem tenta adaptar os problemas de IA a um mundo sistematizado da lógica simbólica, onde seu principal interesse é a maneira de representar relações e características de um problema através do uso de expressões da lógica simbólica e também ampliar o limite das possibilidades para estes tipos de expressões (Martins \& Moraes, 2013).

Frames: representada por Marvin Minsky, afirma que o comportamento do cérebro humano é muito complexo para ser expresso dentro da lógica simbólica. Para isso, o autor propõe a utilização de "frames" como uma combinação de ferramentas e métodos que podem descrever as atividades do cérebro humano sem permanecer confinado à lógica simbólica. A lógica simbólica é geralmente referida como abordagem declarativa, enquanto esta última abordagem é chamada de procedimental (Minsky, 1975).

Redes Semânticas: uma rede semântica nada mais é do que um conjunto de nós conectados. Os nós representam objetos do mundo real, por exemplo, e os arcos são as relações binárias entre estes objetos. O objetivo de uma rede semântica é apresentar uma definição mais clara do conceito que se deseja explicar ou conhecer sobre um determinado ambiente a partir do que está relacionado (Freitas, 2003).

Neste trabalho a forma escolhida para realizar a representação de conhecimento sobre redes de transporte coletivo foi através de ontologias. A seção seguinte discute o assunto, apresentando o que é ontologia, como utilizá-la e os seus principais benefícios e vantagens.

\section{Ontologia}

A palavra ontologia teve a sua origem através de pensamentos filosóficos de Aristóteles.
A computação readquiriu este termo, inserindo-o em um novo contexto, apesar de próximo do significado original. Dentre as dimensões da metafísica, a ontologia trata do ser enquanto ser. Neste sentido, apesar dos múltiplos significados do ser, ele faz referência a um único princípio, que une todos estes múltiplos significados (Isotani \& Bittencourt, 2015).

Vários trabalhos sobre ontologias são encontrados na literatura, e diversas definições sobre este termo são apresentadas (Bandeira et al., 2015). No entanto existe uma definição simples e completa: "Uma ontologia é uma especificação formal e explícita de uma conceitualização compartilhada" (Gruber, 1993). Nessa forma de definição, "formal" significa legível para computadores; "especificação explícita" diz respeito a conceitos, propriedades, relações, funções, restrições, axiomas, explicitamente definidos; "compartilhado" quer dizer conhecimento consensual; e "conceitualização" diz respeito a um modelo abstrato de algum fenômeno do mundo real (Borst, 1997).

Ontologias têm sido utilizadas em diversas aplicações computacionais, por exemplo, em Arquitetura de Redes Ópticas, em representação de sistemas de recomendação educacional, ontologias de domínio voltadas para folclore e cultura popular, entre outras (Pereira et al., 2016). A necessidade em apresentar de forma estruturada e organizada um vocabulário comum, usado em consenso por uma comunidade tem sido de importante para os desenvolvedores de soluções informatizadas [Noy \& Guiness (2002), Isotani\& Bittencourt (2015)].

$\mathrm{O}$ uso tem sido bastante difundido em áreas como: Inteligência Artificial, Engenharia do Conhecimento e Ciência da Computação, comércio eletrônico, processamento de linguagens naturais, recuperação da informação na $W e b$, de cunho educacional, bioinformática, design e integração de banco de dados, entre outras áreas (Bandeira et al., 2015).

$\mathrm{Na}$ seção seguinte são apresentados os benefícios e as vantagens de utilização de ontologias na computação.

\section{Vantagens e Benefícios do Uso de Ontologias}

A utilização de ontologias apresenta muitos benefícios, dentre eles os mais relevantes e que justificam a sua utilidade para o domínio deste 
trabalho podem ser verificados abaixo, conforme é apresentado em Pereira et al. (2016).

a. Oportunidade de compartilhamento do conhecimento entre agentes humanos e de software, uma vez que a ontologia criada representa uma compreensão compartilhada sobre um conjunto de termos e descrições sobre o domínio de transporte coletivo, ainda que em fase inicial, e descrevem de forma precisa as propriedades deste ambiente e os vários conceitos utilizados. Esta oportunidade permite, por exemplo, minimizar a falta de semântica na busca e recuperação de informações sobre horários e um determinado ônibus, por exemplo.

b. Oportunidade de aquisição de "novos" conhecimentos que podem ser adquiridos mais facilmente pelos usuários. Por exemplo, a partir do conhecimento compartilhado pela ontologia, ao pesquisar sobre um determinado trajeto é possível que o usuário possa conhecer facilmente mais informações sobre o mesmo. Tudo isso, através de um motor de inferência que trabalha junto com a ontologia, permitindo que o conhecimento apresentado possa ser feito de maneiro menos custosa para os usuários.

c. Oportunidade de integração e reuso do conhecimento compartilhado pela ontologia desenvolvida. Esse tópico permite que diferentes ontologias, armazenadas em diferentes locais e criadas por diferentes autores, possam ser associadas com esta ontologia e reutilizadas para compor uma ontologia em larga escala sem a necessidade de começar do zero. Outra vantagem está na oportunidade de se reutilizar, de forma menos custosa, o conhecimento associado a uma rede de transporte coletivo, por exemplo.

\section{Ferramentas de Apoio para o desenvolvimento de Ontologias}

Construir uma ontologia é uma tarefa árdua e que consome um grande espaço de tempo, ainda mais se o desenvolvedor tiver necessidade de implementala diretamente na linguagem de ontologia sem apoio de uma ferramenta. A fim de solucionar esse problema foram criados os primeiros ambientes para construção e desenvolvimento de ontologias (Protégé, 2016). Dois exemplos de ambientes para o desenvolvimento de ontologias são apresentados a seguir.

Protégé:éuma ferramentapara desenvolvimento de ontologias criada em 1987, pelo grupo Stanford Medical Informatics - SMI da Universidade de Stanford, seu objetivo inicial era ser uma ferramenta limitada a um sistema especial de oncologia. $\mathrm{O}$ Protégé é uma plataforma de código aberto e gratuito, editor gráfico de ontologias com arquitetura baseada em Java, que fornece ferramentas a uma crescente comunidade para a construção de aplicações de modelo de domínio e de base de conhecimento a partir de ontologias. Possui atualmente mais de 100.000 usuários registrados.

A Figura 1 apresenta um exemplo de ontologia desenvolvida através da ferramenta Protégé. O Protégé pode ser obtido a partir do endereço: http:// protege.stanford.edu/.

OntoStudio: É uma ferramenta comercial para criação e manutenção de ontologias. Tem grande destaque devido às funções com grande abrangência na modelagem intuitiva ontológica. É capaz de realizar importação de diversas estruturas, esquemas e modelos. A ferramenta pode ser obtida através do endereço http://www.semafora-systems.com/ en/products/ontostudio/. A Figura 2 apresenta uma screenshot do OntoStudio.

Existem várias outras ferramentas que possibilitam o desenvolvimento de ontologias. Entretanto, optou-se neste trabalho por apresentar duas das ferramentas mais utilizadas para a realização desta tarefa. Para o desenvolvimento da ontologia proposta neste estudo, a ferramenta Protégé foi escolhida.

\section{Metodologias para Construção de Ontologias}

Metodologias para a construção de ontologias ainda se encontram pouco desenvolvidas (Hinz, 2006). Devido à ausência de uma metodologia formal estabelecida para a realização desta tarefa, uma prática muito comum entre os desenvolvedores de ontologias é passar diretamente do passo de aquisição de conhecimento para o passo de implementação, o que gera certos problemas.

Alguns exemplos destes problemas são: os modelos conceituais da ontologia ficam implícitos no código da implementação, dificuldades no desenvolvimento de ontologias complexas, pois a passagem da aquisição de conhecimento para a implementação é muito repentina, entre outros. 


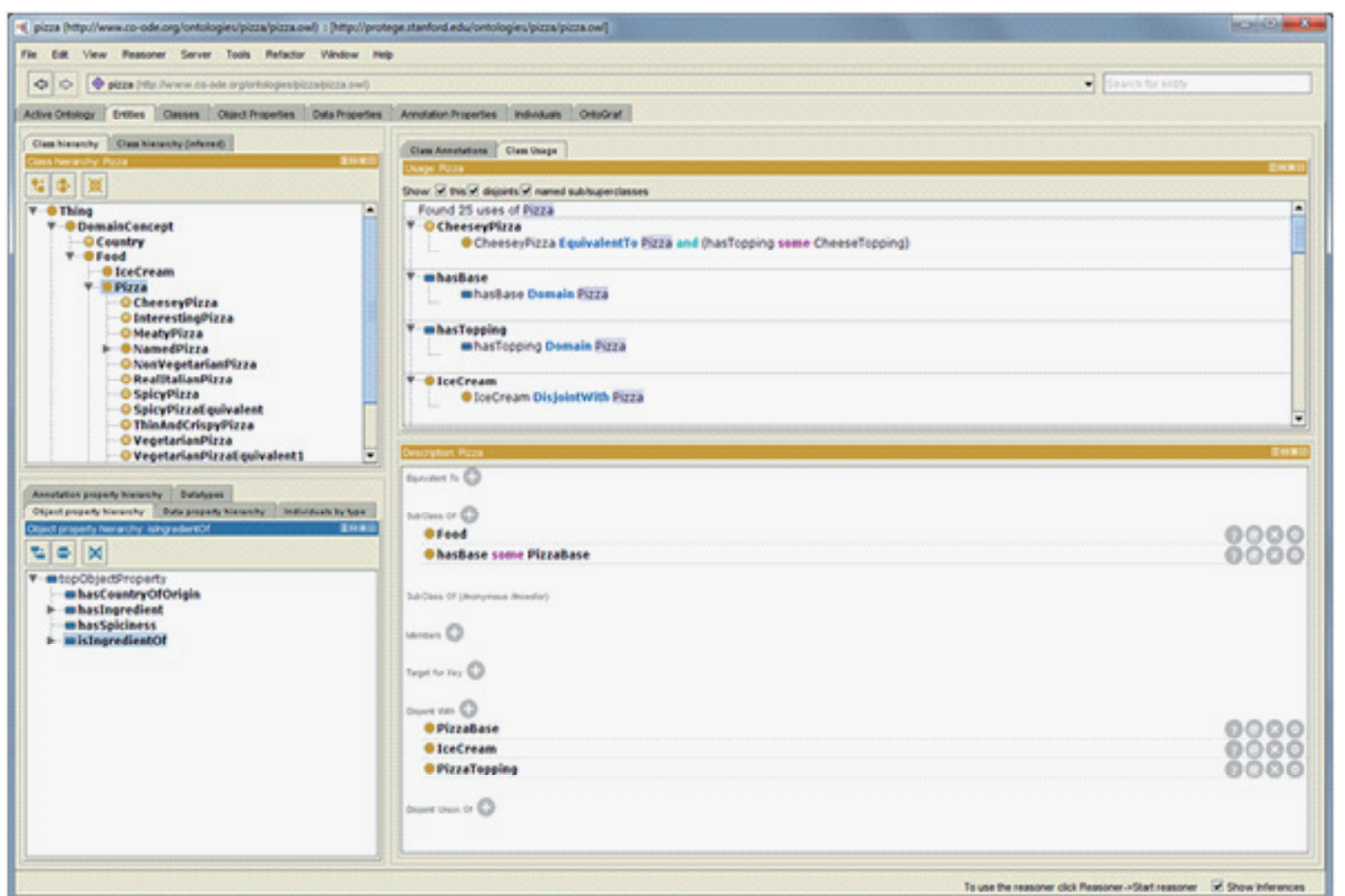

Figura 1. Ferramenta Protégé (Fonte: Captura da tela principal da ferramenta Protégé feita pelo autor).

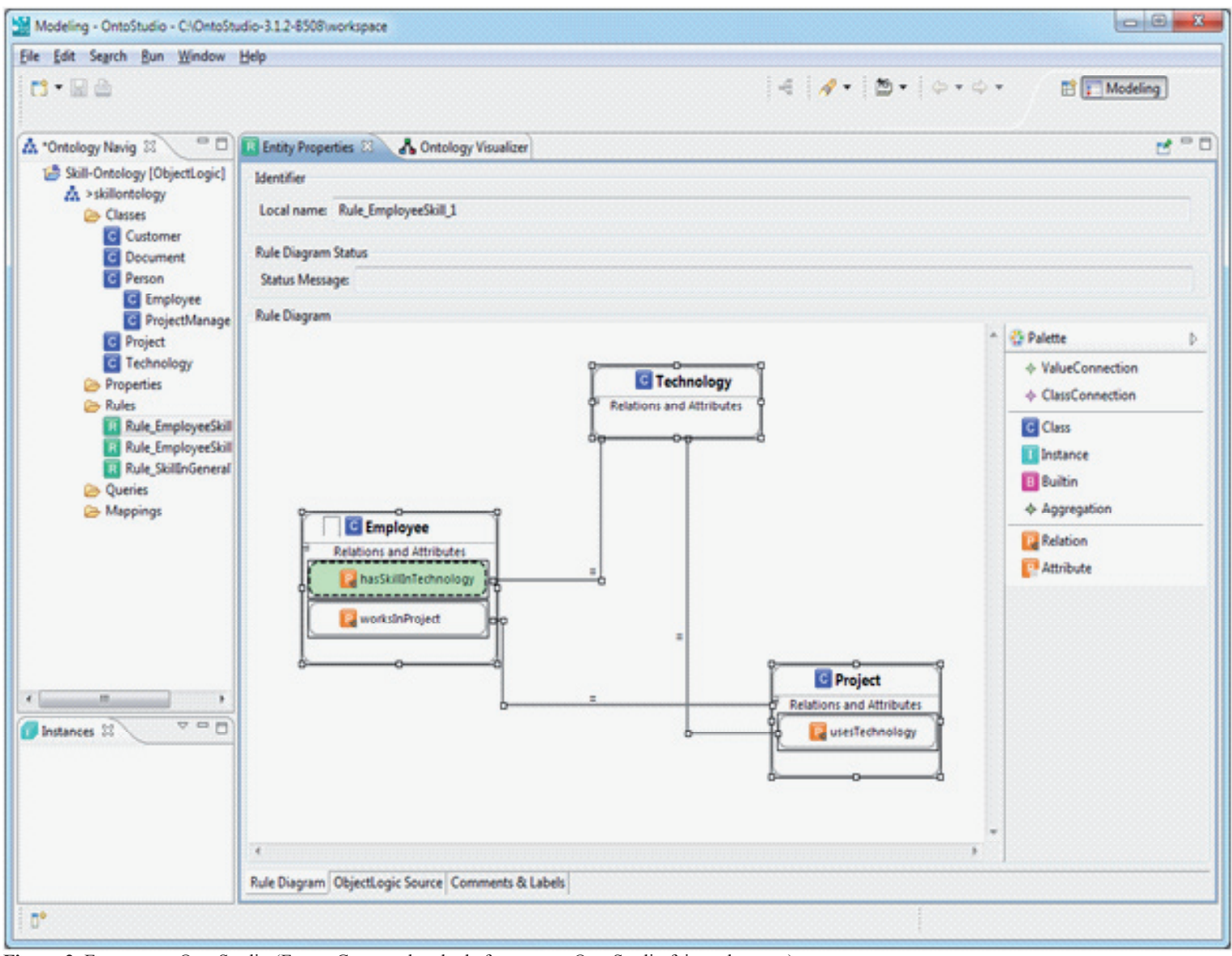

Figura 2. Ferramenta OntoStudio (Fonte: Captura da tela da ferramenta OntoStudio feita pelo autor). 
Apesar da ausência de uma metodologia formal para o desenvolvimento de ontologias, alguns trabalhos iniciais tentaram sistematizar a construção e a manipulação destes artefatos, como por exemplo, no trabalho de (Almeida, 2003).

Conforme apresentado acima, não existe uma maneira definida, padrão, para a criação de ontologias. Esta atividade pode ser efetuada de diversas formas. Porém, existem sete passos, propostos por Baaderet al. (2003) que podem auxiliar nessa atividade. São elas:

a. Determinação do domínio e escopo da ontologia: Primeiro passo a ser tomado.

b. Reutilizar uma ontologia pré-existente: É considerável a existência de uma ontologia semelhante ou se existe alguma possibilidade em refinamento e extensão de uma ontologia existente para a tarefa específica.

c. Levantamento de termos importantes: Listar os termos a serem utilizados e suas propriedades, e o que pode ser dito sobre esses termos.

d. Definição de classes e hierarquia: Definição de classes e subclasses definindo as classes mais genéricas e através delas fazer uma especialização na maioria dos casos.

e. Definição das classes (slots): Uma classe sozinha não apresenta nenhum resultado, é necessário a partir da classe definir a estrutura interna. Exemplo: Carro: modelo, cor, ano fabricação, dentre outros termos a serem utilizados

f. Restrição de propriedades (facetas): Os slots podem possuir diferentes slots com restrições de string, ou seja, o número máximo de caracteres

g. Criação de instância: Ocorre a definição de instâncias para as classes, escolhe uma classe, escolhe uma instância individual e preenche os valores dos slots. Para o desenvolvimento da ontologia apresentada neste trabalho, foi esta a metodologia adotada. Ela é detalhada na seção seguinte.
A construção de uma ontologia que descreve o conhecimento envolvido em uma rede de transporte coletivo é o foco deste trabalho. Por rede de transporte coletivo, entende-se como sendo uma rede composta por uma ou mais empresas que atendem a determinadas linhas de ônibus, ofertando serviço de transporte à população.

Sendo assim, acredita-se que descrever uma ontologia para este cenário seja relevante por ser um domínio repleto de conhecimentos importantes para os usuários deste meio. Além disso, as próprias empresas, responsáveis por ofertar o serviço de transporte, podem se beneficiar desta maneira de representação do conhecimento, por exemplo, a partir das informações dispostas na ontologia uma empresa de transporte pode visualizar como os seus ônibus estão sendo aproveitados nas linhas disponíveis e organizar melhor os seus itinerários.

A ontologia desenvolvida é chamada de OTNet e tem como objetivo principal promover o compartilhamento e reuso de conhecimento sobre o uso de redes de transporte coletivo. Tudo isso, estruturando e representando o conhecimento essencial existente sobre o domínio, de maneira que possa facilitar a busca de informações sobre os meios de transportes coletivos disponíveis para os usuários.

A ontologia OTNet pode ser considerada uma ontologia de aplicação. Uma ontologia de aplicação tem por definição ser mais específica, isso porque são utilizadas dentro de outras aplicações, por exemplo, uma aplicação web pode acessar as informações presentes em uma ontologia. Ela especializa conceitos tanto das ontologias de domínio como da ontologia de tarefa.

A grande vantagem associada à sua utilização neste domínio está relacionada com a oportunidade de realizar inferências sobre o contexto e assim possibilitar a descoberta de outros conhecimentos sobre este cenário. Outra justificava para o seu uso é quanto ao esforço necessário para obter conhecimento sobre o domínio.

\section{Descrição da Ontologia OTNet}

Para a definição do escopo da OTNet foram formuladas algumas questões essenciais que deveriam ser respondidas pela ontologia, e são descritas a seguir:

a. Quais ônibus pertencem a uma determinada rede 
de transporte?

b. Quais são os ônibus que cumprem uma determinada linha?

c. Qual trajeto (rota) é feito por uma determinada linha?

d. Quais são os pontos de paradas de uma linha em um determinado trajeto?

e. Quais são os horários de ônibus de uma determinada linha?

Para que a OTNet possa desempenhar o seu papel dentro de uma aplicação, uma carga com alguns dados considerados relevantes para formar o conhecimento inicial foi realizada. Esta carga incluiu na OTNet novos indivíduos, para que inferências possam ser feitas e outros conhecimentos sobre o domínio possam ser apresentados para os usuários.

Um fator importante de ressaltar é que a ontologiaOTNet, assim como qualquer contexto, pode evoluir, incorporando novos termos, regras, entre outros. Para isso, se a diferença for terminológica, a ontologia pode permitir que as regras sejam traduzidas, os termos alterados e assim funcione corretamente no novo ambiente compartilhado no qual esteja inserida.

\section{Implementação da Ontologia}

Para o desenvolvimento da ontologia proposta neste trabalho a ferramenta Protégé foi escolhida devido a mesma ser a mais utilizada no meio acadêmico, possuir uma boa interface de interação com o usuário e apresentar bons resultados (Schaefer, 2004).

As classes, propriedades e termos definidos e utilizados na concepção da OTNet foram definidos e são apresentados em inglês de forma que possa colaborar para a evolução e/ou conexão desta ontologia com outras, no futuro. A partir da descrição apresentada acima, as classes que compõe a ontologia inicialmente, são apresentadas na figura 3 , e as propriedades de relacionamento entre as classes são apresentadas pela figura

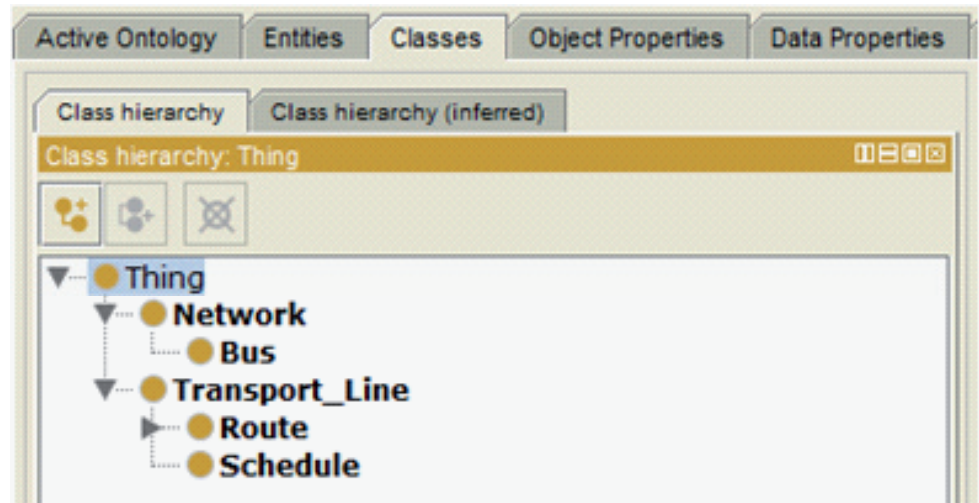

Figura 3. Classes da Ontologia OTNet (Fonte: Tela capturada da ontologia criada no Protégé).

\begin{tabular}{|c|c|c|c|c|c|c|c|}
\hline \multicolumn{3}{|c|}{ Active Ontology } & Entries & Classes & Object Properties & Data Properties & Annotation Propert \\
\hline \multicolumn{7}{|c|}{ Object property hierarchy topObjectProperty } & 프밈 \\
\hline$\tau$ & E & $x$ & & & & & \\
\hline 7- & 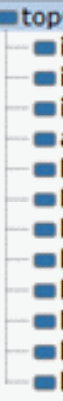 & $\begin{array}{l}\text { Obje } \\
\text { is_at } \\
\text { is_pa } \\
\text { is_at } \\
\text { atten } \\
\text { belor } \\
\text { belor } \\
\text { belor } \\
\text { belor } \\
\text { has_- } \\
\text { has_- } \\
\text { has_- } \\
\text { has_ }\end{array}$ & $\begin{array}{l}\text { tProper } \\
\text { tended } \\
\text { rt_of } \\
\text { tended } \\
\text { d_line } \\
\text { gs_to_- } \\
\text { gs_to_- } \\
\text { gs_to_ } \\
\text { gs_to_- } \\
\text { bus } \\
\text { bus_sto } \\
\text { route } \\
\text { schedul }\end{array}$ & $\begin{array}{l}\text { by } \\
\text { by_bus } \\
\text { us_stop } \\
\text { petwork } \\
\text { route } \\
\text { ransport } \\
\text { p }\end{array}$ & e_line & & \\
\hline
\end{tabular}


4.OsDataProperties são os dados sobre as classes criadas na ontologia, e foram definidos de maneira simples, por exemplo, armazenando apenas dados essências, tais como nome e uma identificação.

Abaixo, as classes criadas são explicadas, bem como os relacionamentos existentes entre elas.

ClasseNetwork: Esta classe diz respeito às empresas que formam uma rede de transporte coletivo. Por exemplo: Viação Pedro Antônio na cidade de Vassouras, Viação Transa Transportes na cidade de Três Rios, Viação Princesa da Serra localizada em Valença, entre outras.

Algumas destas empresas citadas acima foram utilizadas como indivíduos na OTNet de maneira que esta pudesse ser populada para apoiar a descoberta de novos conhecimentos a partir de um motor de inferência. Os motores de inferência são discutidos na próxima seção. A figura 5 apresenta alguns destes indivíduos.

A classe NetWork se relaciona com os

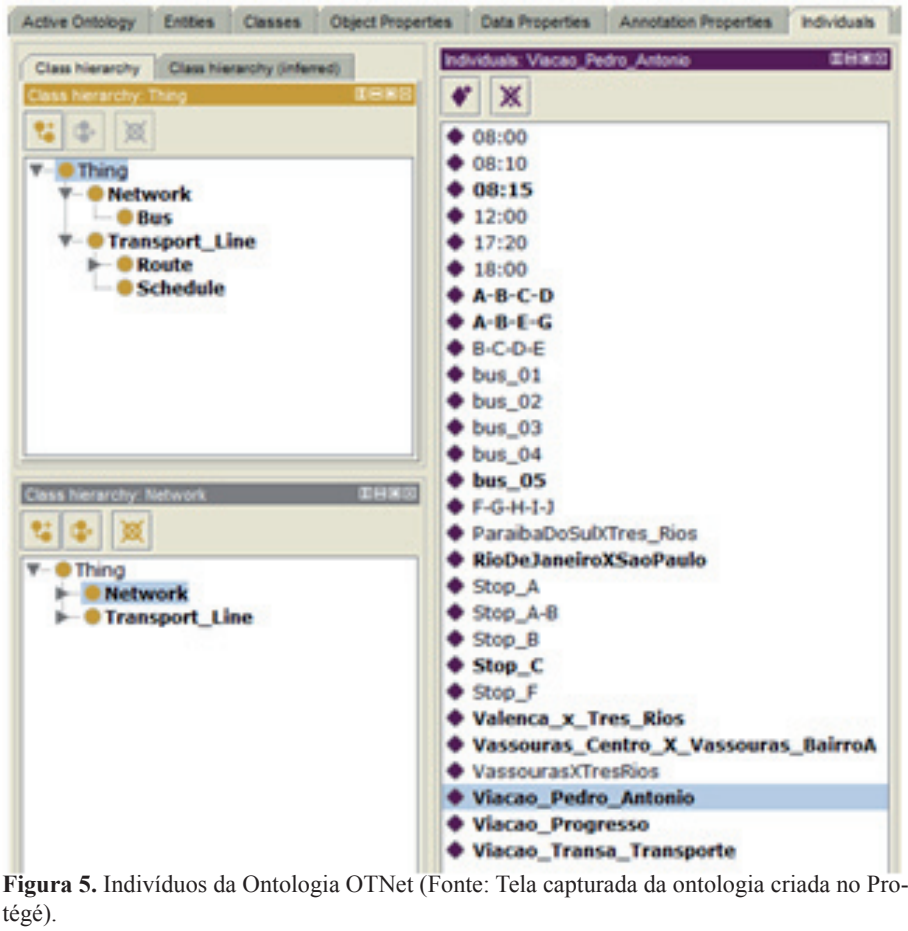

ônibus que estão cadastrados como indivíduos na ontologia da seguinte maneira: uma propriedade funcional chamada has_bus foi criada onde indica que toda rede de transporte tem pelo menos um ônibus. Para assegurar que o contrário também seja verdadeiro, outra propriedade inversa funcional foi criada, chamada de belongs_to_network. A figura 6 , mostra de forma gráfica este relacionamento.

Classe Transport_Line:Essa classe armazena

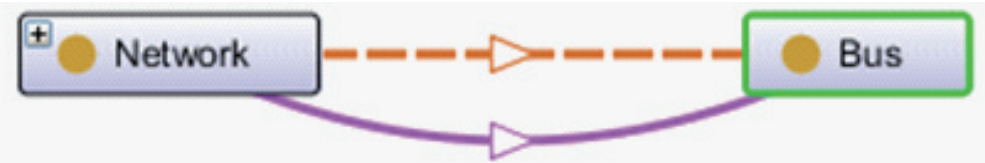

Figura 6. Relacionamento entre as classes Network e Bus (Fonte: Tela Capturada da ontologia criada no Protégé) 
informações a respeito das linhas de transportes, ou seja, as linhas que são percorridas pelos ônibus. Por exemplo: Valença x Juparanã, São José das Palmeiras, Valença x Três Rios, entre outras.

A classe Transport_Line se relaciona com a classe Route, que é a responsável por determinar a rota (trajeto) a ser percorrido por um determinado ônibus. A mesma se relaciona da seguinte maneira: uma propriedade funcional chamada has_route foi criada e indica que a linha de transportes tem determinada rota a ser seguida. Para garantir que o contrário também fosse verdadeiro, foi criada uma propriedade inversa funcional, chamada de belongs_to_transport_line. A figura 7 ilustra este relacionamento.

A classe Bus_Stop, é a classe que fornece informações a respeito dos pontos de parada das linhas de transporte, através de determinação de sua rota. Ela se relaciona com a classeRoute, da seguinte maneira: uma propriedade chamada has bus_stop foi criada, na qual consiste em dizer que naquele determinado local da rota, existe um ponto de parada, seguindo determinações da linha. Este relacionamento é apresentado na Figura 8.

A classe Schedule, é referente aos horários dos ônibus, classe essa que está diretamente ligada a linha de transportes. Essa classe determina o horário a ser seguido pela linha de transporte, ela irá designar o horário específico. Exemplo: horário 9:30 - Linha Valença x Juparanã. A mesma se relaciona com a classe Transport_Line através da seguinte propriedade: has_schedule, cujo significado é que tem horário. $\mathrm{O}$ relacionamento entre estas duas classes é apresentado pela Figura 9.

Outras classes poderão ser adicionadas no futuro. Esta ontologia traz a representação

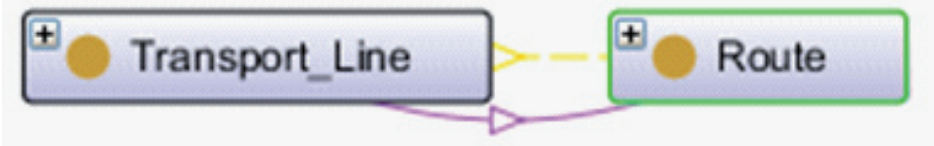

Figura 7. Relacionamento entre as classes Transport_Line e Route (Fonte: Tela Capturada da ontologia criada no Protégé).

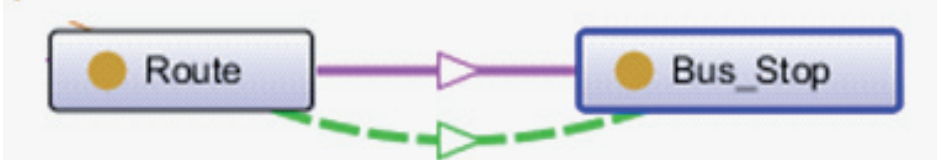

Figura 8. Relacionamento entre as classes Route e Bus_Stop (Fonte: Tela Capturada da ontologia criada no Protégé).

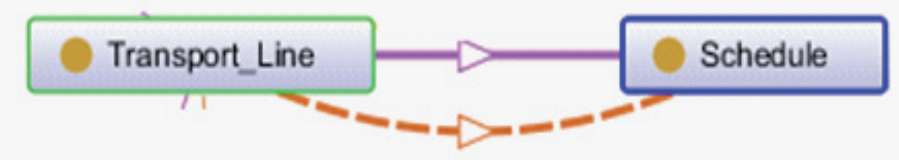

Figura 9. Relacionamento entre as classes Transport_Line e Schedule (Fonte: Tela Capturada da ontologia criada no Protégé). 
inicial e de forma bem essencial sobre o contexto de transportes coletivos sob a perspectiva de um usuário destes meios de transporte. A OTNet foi implementada utilizando a linguagem OWL (Ontology Web Language) na versão 2, por incorporar facilidades para publicar e compartilhar a ontologia proposta na web. Ela pode ser acessada através do endereço: https://goo.gl/WdRVTF.

\section{Motor de Inferência}

Em essência, os motores de inferências são softwares cujo objetivo é possibilitar a geração de hipóteses com base nas informações que estão disponíveis nas bases de conhecimento (Barros, 2015), como em uma ontologia, por exemplo, executando as regras escritas nela objetivando alcançar respostas em um processo de inferência. Os motores de inferência também são conhecidos como raciocinadores ou ainda como máquinas de inferências.

Conforme foi apresentado acima, o raciocinador avalia uma ontologia de acordo com sua consistência e organiza a sequencia de ações ou de regras que serão executadas por elas de maneira que aconteça assim a descoberta de novos conhecimentos (Barros, 2015).

Como exemplos de motores de inferência, pode-se citar o Pellet, o RacerPro, HermiT, entre outros. Neste trabalho a máquina de inferência escolhida foi o HermiT, versão 1.3.7. Isso por que este raciocinador é utilizado para ontologias escritas usando a OWL (Ontology Web Language). Além disso, o HermiT é primeiro raciocinador OWL que fornece raciocínio muito mais eficiente do que qualquer algoritmo previamente conhecido (Barros, 2015). A figura 10, mostra o Hermit sendo utilizado na ontologia OTNet.

A seção seguinte mostra os resultados inferidos na ontologia desenvolvida neste trabalho através do uso do motor de inferência HermiT.

\section{Cenário de Uso da Ontologia OTNet}

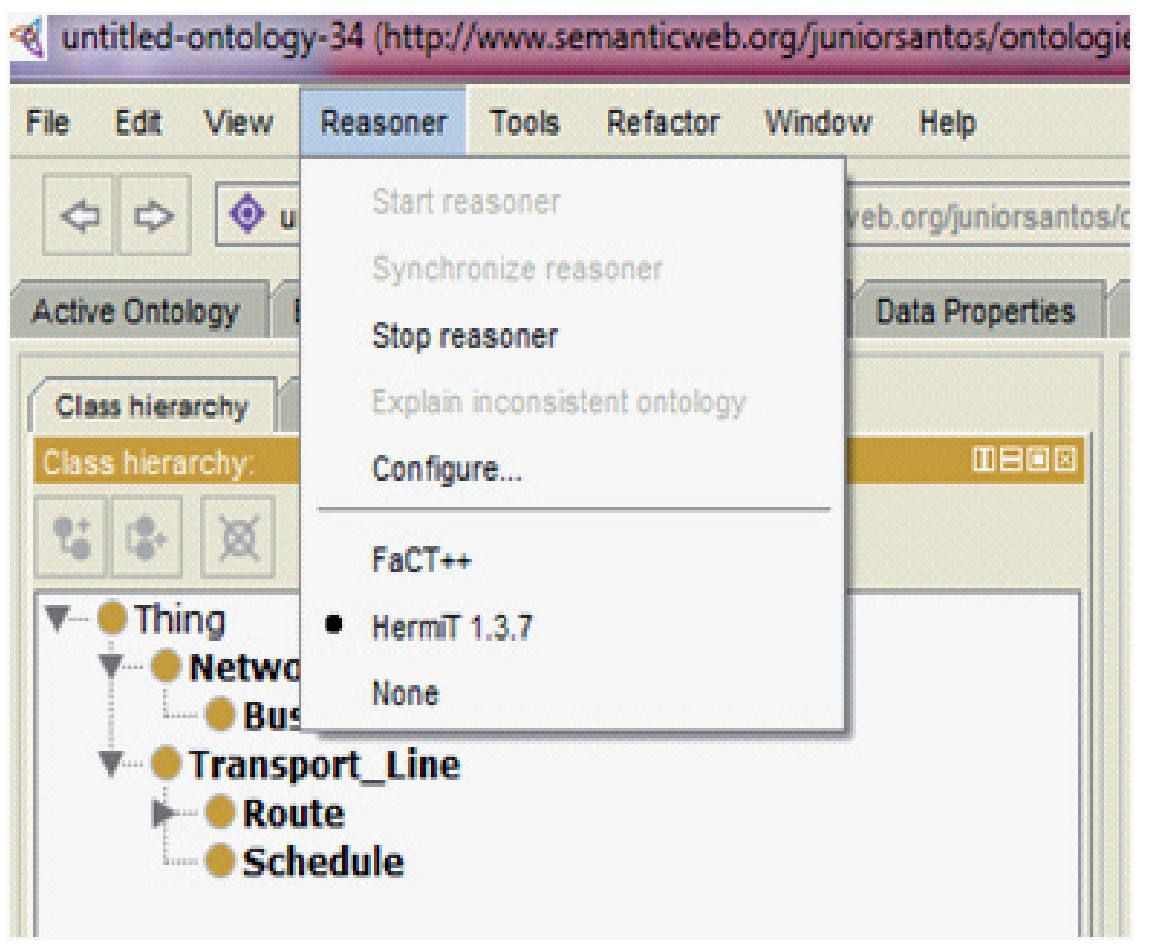

Figura 10. ReasonerHermiT 1.3.7 (Fonte: Tela Capturada do resultado inferido no Protégé). 
A seguir é apresentado um breve cenário de uso. Este cenário foi descrito para mostrar a relevância da ontologia OTNet para o domínio que está inserida. A Figura 11 ilustra este cenário.

Nele, um usuário identificado como "A" realiza uma busca por informações sobre uma determinada linha de ônibus intermunicipal, Vassouras X Três Rios. Vale ressaltar que neste trabalho não é apresentada uma aplicação para a conexão com a ontologia OTNet, por exemplo, uma aplicação móvel através da qual um usuário possa realizar a consulta. Para este cenário, assume-se que esta aplicação móvel exista, de maneira que o usuário "A" possa realizar a sua consulta através de um dispositivo móvel que se conecta diretamente com a OTNet. Isso por que, caso um usuário comum venha a realizar um consulta diretamente na ontologia, o mesmo precisaria ter conhecimento da linguagem de pesquisa utilizada por ontologias, conhecida como SPARQL e este não foi o foco deste trabalho.

A partir das inferências realizadas na ontologia e das regras descritas, o usuário "A" tem como retorno as informações apresentadas na figura 12. Para que o conhecimento apresentado possa ficar mais claro, o resultado foi apresentado diretamente no Protégé.

$\mathrm{Na}$ figura 12 é possível perceber que ao pesquisar por VassourasXTresRios, que é um indivíduo na ontologia, o raciocinador infere que
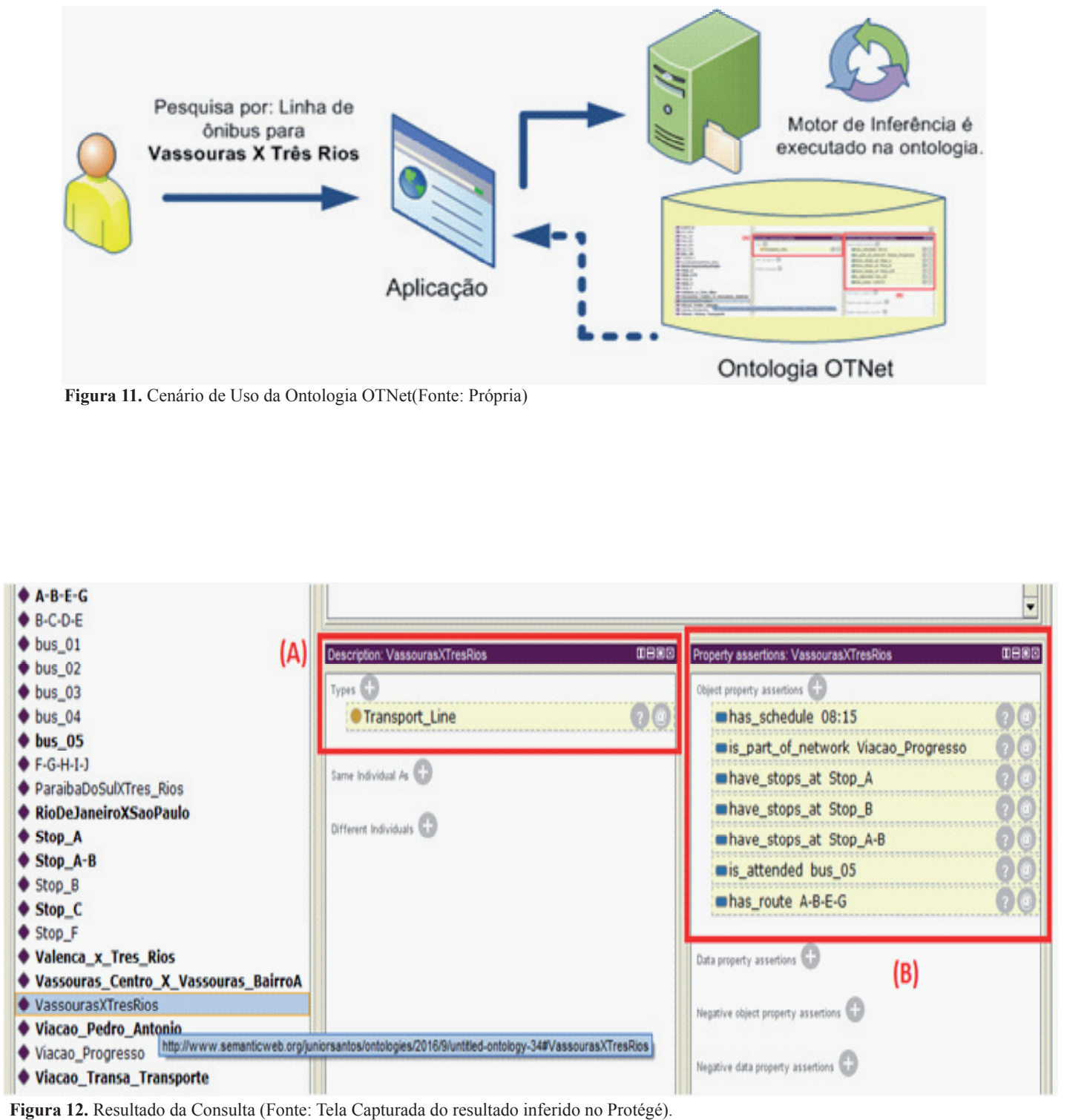
o termo pesquisado é uma linha de transporte (A). Além disso, baseadas nas regras que foram especificadas no desenvolvimento da OTNet, apenas pesquisando por uma terminada linha o usuário pode conhecer muitas informações relevantes sobre ela conforme pode ser observado no quadro B da figura 12. Por exemplo: (i) é possível conhecer os horários atendidos pela linha; (ii) a empresa de ônibus responsável pela linha, que no cenário acima é a Viação Progresso; (iv) é possível conhecer todos os pontos de parada de ônibus disponíveis naquela linha pesquisada; (v) O ônibus que atende a linha VassourasXTrêsRios; e (vi) por último, é conhecer a rota que será feita pelo ônibus que percorre a linha.

A grande vantagem que se percebe no uso de uma ontologia para manter a representação do conhecimento sobre este domínio, está na

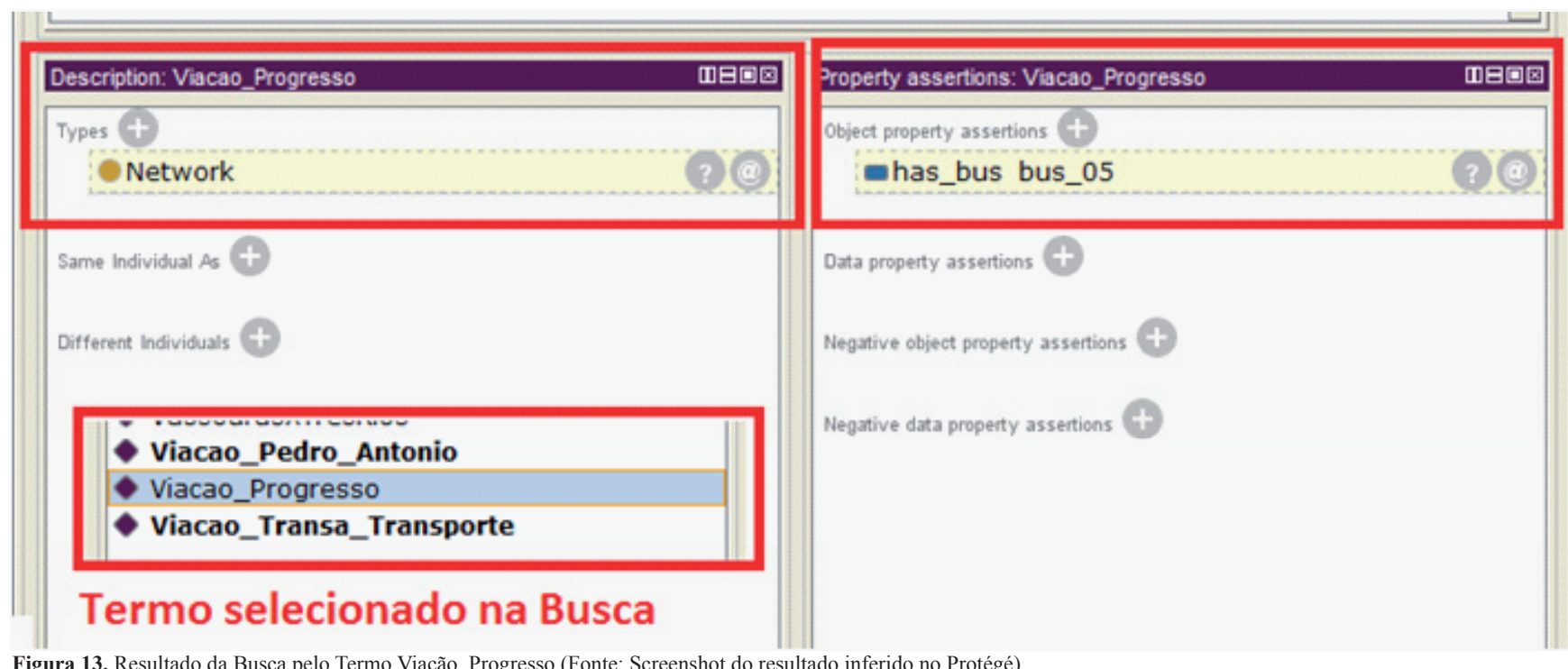

Figura 13. Resultado da Busca pelo Termo Viação Progresso (Fonte: Screenshot do resultado inferido no Protégé).

oportunidade de oferecer aos usuários informações mais precisas e relevantes a um custo menor, visto que, uma vez que as regras sobre o cenário foram definidas e implementadas, conforme a ontologia é alimentada, o resultado inferido e apresentado tem mais semântica e colabora efetivamente para que o usuário possa conhecer mais sobre o meio que está pesquisando e assim tomar a sua decisão.

Outros resultados inferidos na ontologia OTNet são apresentados abaixo. Na figura 13, por exemplo, é possível conhecer o resultado ao buscar por Viação_Progresso na OTNet.

O resultado inferido apresenta que Viação Progresso é uma Rede (Empresa de Transporte) e que ela possui ou é responsável pelo ônibus 5 (bus_05). $t$ do resultado inferido no Protégé).

Outro exemplo de resultado é busca por um determinado horário na OTNet. Um usuário identificado como usuário " $\mathrm{C}$ " realiza a busca pelo horário de $08: 10$, com resultado inferido pela OTNet são apresentados os valores destacados na Figura 14.

Ao pesquisar pelo termo 08:10 é inferido que este termo é um horário (mais dados sobre o termo pode ser adicionados no futuro, como por exemplo, dias de semana em que o horário está disponível, entre outros), que ele é atendido pelo ônibus 03 e que este horário é referente a linha Valenca_X_ Tres Rios.

Para o desenvolvimento da OTNet apenas algumas regras foram definidas inicialmente sobre o cenário de Transporte Coletivo. O objetivo principal foi mostrar como ontologias podem ser utilizadas em cenários mais simples para atender um determinado público de usuários. No futuro, novas regras poderão ser criadas de maneira que 


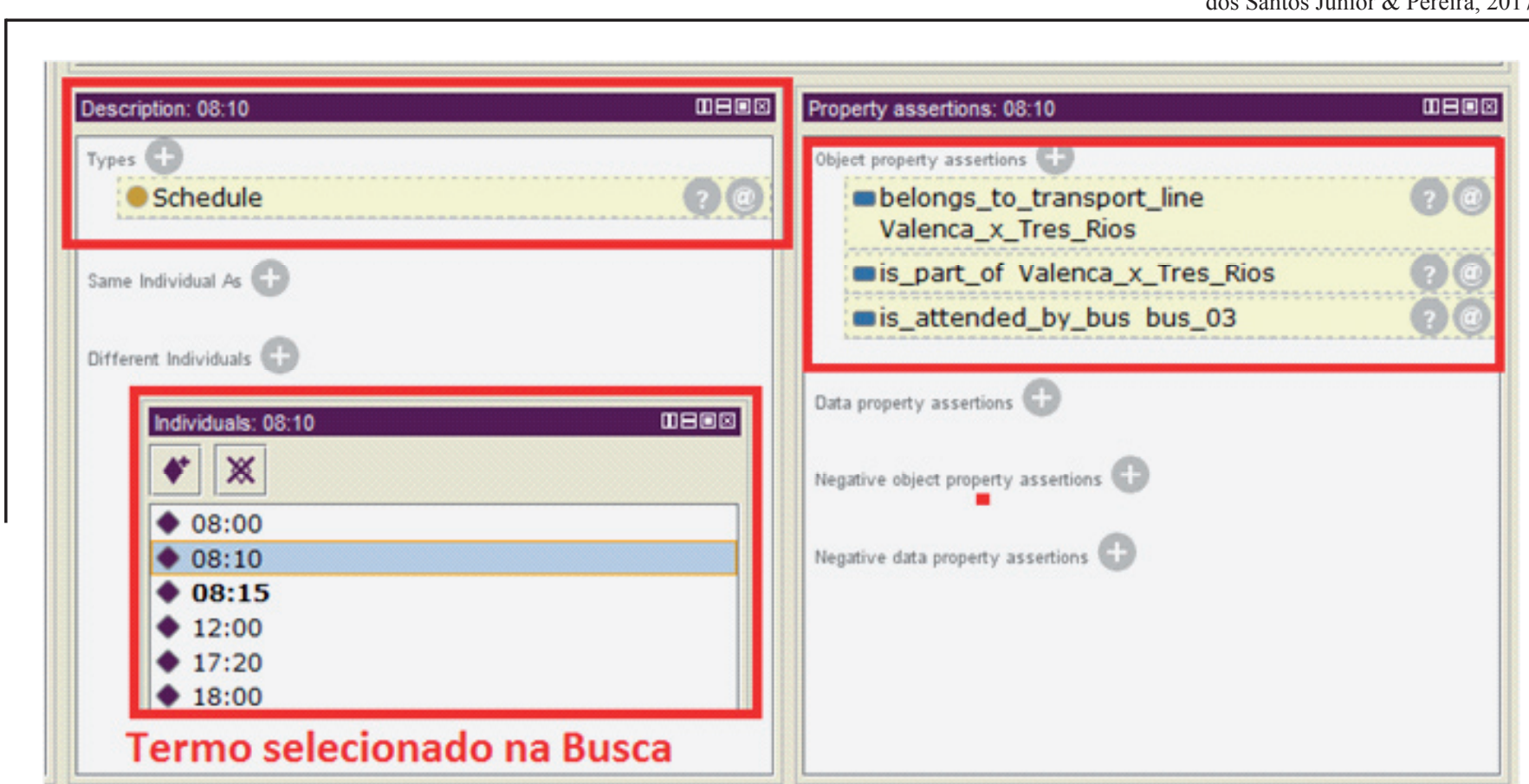

Figura 14. Resultado da Busca pelo Termo 08:10 (Fonte: Screenshot do resultado inferido no Protégé).

mais conhecimento sobre o domínio possa ser "descoberto".

\section{Considerações Finais}

Neste trabalho foi investigado formas para representação de conhecimento utilizada na literatura, de forma que pudesse apoiar o desenvolvimento de algum mecanismo para estruturar e organizar o conhecimento sobre uma rede de transporte coletivo rodoviário. Identificada as principais formas encontradas na literatura, a maneira escolhida foi a utilização de ontologias.

Ontologias vêm sendo empregadas em vários contextos e explorar o seu uso no cenário de transporte coletivo rodoviário pode trazer benefícios para os usuários, tais como oferta de informações mais precisas por exemplo. Para isso, uma ontologia chamada OTNet foi desenvolvida e foi apresentada neste trabalho.

A OTNet apresenta inicialmente informações essenciais sobre uma rede de transporte rodoviário, tais como, informações sobre rotas, horários de ônibus, linhas, pontos de paradas, entre outras. A partir dela é possível inferir novos conhecimentos sobre este domínio, de maneira que as informações oferecidas para os usuários sejam mais relevantes e atualizadas.

Entretanto, não foi desenvolvida nenhuma ferramenta para conexão com a ontologia proposta neste trabalho. Sendo assim, inicialmente os resultados gerados são apresentados a partir das inferências feitas pelo motor de inferência HermiT. Para consultas mais complexas, SPARQL pode ser utilizado, mas não é esse o foco do trabalho.

Sendo assim, como trabalho futuro deseja-se desenvolver um aplicativo móvel que possa servir como interface para que usuários de transportes coletivos rodoviários possam utilizá-lo como meio de obter informações sobre este domínio. Além disso, a ontologia desenvolvida pode ser conectada a outras aplicações seja ela web ou desktop, de maneira que possa colaborar para geração e descoberta de novos conhecimentos no contexto de redes de transporte e ainda apoiar a coleta e representação de conhecimento de maneira formal sobre este domínio.

\section{Referências}

Almeida, M. B., \& Bax. M. P. (2003). Uma visão geral sobre ontologias: pesquisa sobre definições, tipos, aplicações, métodos de avaliação e de construção. Ci. Inf., Brasília, v. 32, n. 3, p. 7-20.

Baader, F., Calvanese, D., Mcguinness, D. L., Nardi, D.,\& Patel-Schneider, P. F. (2003). The Description Logic Handbook: Theory, Implementation, Applications. Cambridge University Press, Cambridge, UK.

Bandeira, J. M., Alcântara, W. L., Sobrinho, A. B., Ávila, T. J. T., Pinto, I. I. B. S., \& Isotani, S. . (2015). Dados abertos conectados. Anais do Simpósio Brasileiro de Tecnologia da Informação.

Barros, P. V. D. S. (2015). Uma abordagem ontológica para modelagem de crimes contra o patrimônio, Dissertação de Mestrado - Ciência da 
Computação. Universidade Federal de Pernambuco. Refice, Pernanbuco.

Brachman, R. J (1990). The Future of Knowledge Representation.In: AAAI. 1990. p. $1082-1092$.

Borst, W. N. (1997). Construction of engineering ontologies. University of Twenty, Enschede, Center for Telematica and Information Technology.

Freitas, F. L. G. (2003) “Ontologias e a web semântica”. Jornada de MiniCursos em Inteligência Artificial, SBC 8.

Guarino, N. (1998). Formal Ontology and Information Systems.Disponível em: http://www.loa-cnr.it/Papers/FOIS98.pdf.

Gruber, T. (1993). What is an Ontology. WWW Site http://www-ksl.stanford. edu/kst/whatis-an-ontology. html.

Hinz, V. T. (2006). Proposta de Criação de uma Ontologia de Ontologias. Trabalho Individual I, Programa de Pós-Graduação em Informática, UCP.

Isotani, S., \& Bittencourt, I. I. (2015). Dados Abertos Conectados: Em busca da Web do Conhecimento. Novatec Editora.

Martins, G. K.,\& Moraes, J. B. E. (2013). Sistematização de conteúdos em organização e representação do conhecimento: um estudo nos periódicos de Ciência da Informação no Brasil. Ribeiro, Fernanda, 421-436.

Minksy, M. (1975).A framework for representing knowledge. The psychology of computer vision, 73, 211-277.

Noy, F. N.; \& Guinness, D. L. (2002) Ontology development 101: a guide to create your first ontology. Stanford University, USA.

Pereira, A. F., Braga, R., \& Campos, F. (2016). An Architecture to Enhance Collaboration in Scientific Software Product Line. In 2016 49th Hawaii International Conference on System Sciences (HICSS) (pp. 338-347).IEEE.

Pinto, T. D. S. (2015). Estudo de mercado: transportes e logística (Doctoraldissertation, Instituto Politécnico do Porto. Escola Superior de Estudos Industriais e de Gestão).

Protégé (2016). Disponível em: http://protege.stanford.edu.

Ramalho, R. A. S. (2010) Desenvolvimento e utilização de ontologias em bibliotecas digitais: uma proposta de aplicação. 2010. 145 f. Tese (Doutorado) - Universidade Estadual Paulista, Faculdade de Filosofia e Ciências.

Rocha, L. B. L., Beauclair, M. G., Silva, A. V. A., Gaspar, M. J. G., \& dos Santos, H. D. S. A. (2012) Ontologia de notícias: um modelo para classificação do conteúdo dos jornais on-line brasileiros, segundo a lógica da Web Semântica.

Schaefer, C. (2004) Protótipo de aplicativo para transmissão de dados a partir de dispositivos móveis aplicado a uma empresa de transportes. Trabalho de Conclusão de Curso, Universidade Regional de Blumenau, Blumenau. 